\title{
Manganese catalyzed hydrogenation of enantiomerically pure esters
}

\author{
Magnus B. Widegren and Matthew L. Clarke* \\ School of Chemistry, University of St Andrews, St Andrews, KY16 9ST, United Kingdom

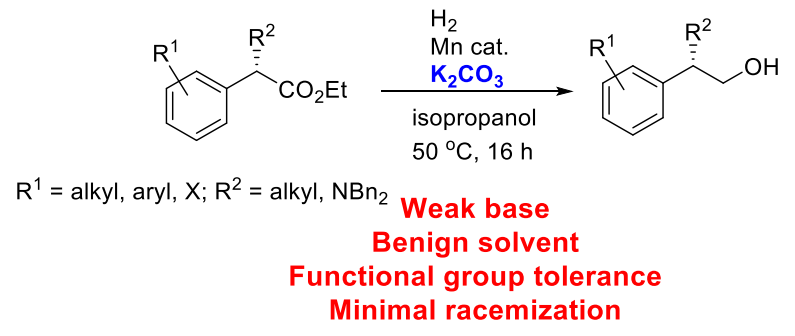

ABSTRACT: A manganese-catalyzed hydrogenation of esters has been accomplished with TON up to 1000, using cheap, environmentally benign, potassium carbonate and simple alcohols as activator and solvent, respectively. The weakly basic conditions lead to good functional group tolerance and enable the hydrogenation of enantiomerically enriched $\alpha$-chiral esters with essentially no loss of stereochemical integrity.

The hydrogenation of esters has developed from a very problematic transformation around 10 years ago into a reaction of developing importance to industrial synthesis. ${ }^{1-}$ ${ }^{5}$ Ruthenium catalysts have been primarily studied for this reaction, ${ }^{6-13}$ although some promising results have also been reported using iron-based catalysts. ${ }^{14-17}$ At present, the TON exhibited by Fe-catalysts (up to $1280^{17}$ ) are significantly lower than those often reported using $\mathrm{Ru}$ systems (up to $100000^{10,19-22}$ ). Most papers, whether they use $\mathrm{Ru}$ or $\mathrm{Fe}$, make use of alkoxide bases as an activator. Such bases are quite expensive, can be intolerant of functional groups and cause racemization of stereogenic centres. There are a small number of cases where the stable, cheaper precatalysts were converted into hydride-borohydride complexes such as $\mathbf{1}^{23}, \mathbf{2}^{24}$ or $\mathbf{3}^{14}$ (Fig. 1) using a large excess of sodium borohydride (10 -25 equivalents) to form catalysts that can operate under base-free. Bifunctional ligands within a catalyst can also be deprotonated prior to catalysis as another pre-activated catalyst option. ${ }^{25-29}$ The procedures with the highest TON reported have tended to use a strong base activator.

The use of manganese reduction catalysts has many of the appealing features of Fe catalysis, since it is a highly abundant non-toxic element; it is a metal of limited concern in pharmaceutical manufacture with tolerance of 250 ppm relative to $5-10$ ppm for precious metals. ${ }^{30}$ Manganese reduction catalysis is now beginning to receive the attention it merits. ${ }^{31-35}$

Recently, we discovered that a manganese complex, 4 (Fig. 1) derived from a PNN ligand, can hydrogenate esters at just $75{ }^{\circ} \mathrm{C}$ using $1 \mathrm{~mol} \%$ catalyst, and $10 \mathrm{~mol} \%$ of the common activator $\mathrm{KOBu}^{\mathrm{t}}$. 31

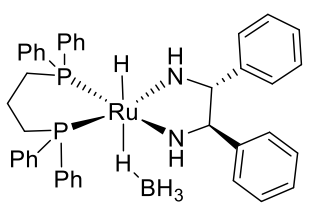

1

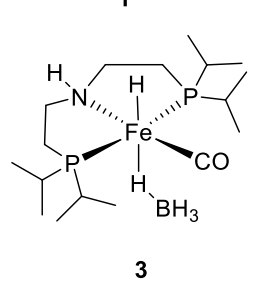

3

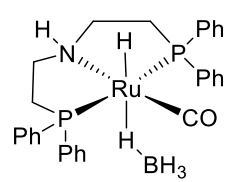

2

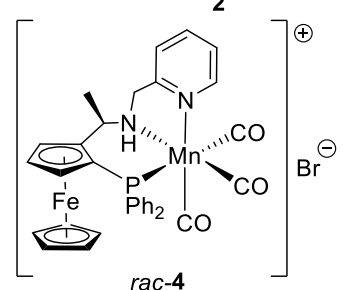

Figure 1. Examples of transition metal catalysts used in ester hydrogenation (Note rac-4 is a 50/50 mixture of $R_{c}$, $S_{p}$ isomer as above and $S_{c}, R_{p}$ isomer).

Other publications reported at this time using manganese also make use of strongly basic activators; ${ }^{32-35}$ most esters were reduced at around $100{ }^{\circ} \mathrm{C}$ using around $1 \mathrm{~mol} \%$ catalyst. To our knowledge, the only earth abundant metal catalyst reducing a range of esters at below $1 \mathrm{~mol} \%$ catalyst loading is a report on a $\mathrm{Mn}$ system that unfortunately required $75 \mathrm{~mol} \%$ of alkoxide activator in order for $0.2 \mathrm{~mol}$ $\%$ of catalyst to be used at $100{ }^{\circ} \mathrm{C} .{ }^{35 a}$ The reactivity exhibited by our un-optimized system implied it might be more reactive than the state-of-the-art manganese hydrogenation catalysts, and that development of practical conditions was a highly worthwhile goal. Here, we show that the ra- 
cemic Mn catalyst, rac-4 can deliver a high TON for an earth-abundant metal system using cheap, environmentally benign solvent and base. The use of the weakly basic conditions allows the hydrogenation of chiral esters with complete retention of configuration.

Table 1. Hydrogenation of achiral esters ${ }^{a}$

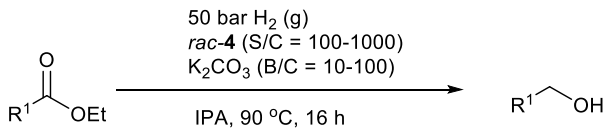

a. Reaction conditions: $1.6 \mathrm{mmol}$ substrate, $0.0016-0.016$

\begin{tabular}{|c|c|c|c|}
\hline entry & product & catalystb & conversion $(\%)$ \\
\hline 1 & & 0.1 & $>99(90)$ \\
\hline $2^{d}$ & & 0.1 & >99 (79) \\
\hline $3^{e}$ & & 0.1 & $>99(90)$ \\
\hline $4^{\mathrm{f}}$ & $6 \mathrm{D}$ & 0.1 & $>99(82)$ \\
\hline 5 & & 0.1 & $>99$ (95) \\
\hline $6^{f}$ & & 0.5 & $>99$ (88) \\
\hline 7 & & 0.1 & $>99(70)$ \\
\hline 8 & & 0.1 & $>99(90)$ \\
\hline 9 & & 0.1 & $>99(85)$ \\
\hline 10 & & 1.0 & $>99(71)^{\mathrm{g}}$ \\
\hline
\end{tabular}

mmol 4, $0.16 \mathrm{mmol} \mathrm{K}_{2} \mathrm{CO}_{3}, 50$ bar $\mathrm{H}_{2}$, ethanol or isopropanol (0.5-0.6 M), $90{ }^{\circ} \mathrm{C}, 16 \mathrm{~h}$, using 1-methylnaphthalene as internal standard; b. catalyst loading in mol \%; c. isolated yield in brackets; $d$. reaction run in isopropanol; e. using 20 bar $\mathrm{H}_{2}$; $\mathrm{f}$. methyl ester of the starting material used; g. isolated as a mixture of cis/trans.

We were delighted to find that we could reduce test substrate ethyl $p$-fluorobenzoate (5a) to the $p$-fluorobenzyl alcohol (6a) using different inorganic bases (see Table S1) using $0.1 \mathrm{~mol} \%$ of catalyst rac-4 at $90{ }^{\circ} \mathrm{C}$. In general, potassium bases performed much better than sodium bases. Potassium hydroxide, carbonate and phosphate stood out as candidates, and we decided to use the inexpensive potassium carbonate as the preferred base. We found that either ethanol or isopropanol could be used as the solvent (Table 1, entry 1-3) and that 5a could be reduced using 20 bar of hydrogen gas (Table 1, entry 3). With these results in hand, we explored these conditions using different substrates (Table 1 ). The catalyst readily reduced aromatic (Table 1 entries 1-6 and 9) and aliphatic esters (entries 7-8 and 10). Functional groups such as bromine (entry 3), amino (entry 6) and pyridine (entry 9) were well tolerated. Oxirane ester $\mathbf{5 h}$ (entry 10) was reduced without loss of the oxirane ring to its corresponding alcohol (6h), although $1 \mathrm{~mol} \%$ of catalyst was required to give good yield.

Ambrox ${ }^{\circledR}$ is used in the fragrance industry as both a fixant and for creating notes of ambergris. One synthetic route to this compound starts from the lactone $R-(+)-$ sclareolide (7a). ${ }^{36-38}$ Using the developed conditions, $7 \mathbf{a}$ was readily reduced to the diol $\mathbf{8 a}$ on a multi-gram scale in good isolated yield (75\%) using $0.1 \mathrm{~mol} \%$ of the catalyst in ethanol (Scheme 1).

\section{Scheme 1. Hydrogenation of sclareolide using catalyst} rac-4a.

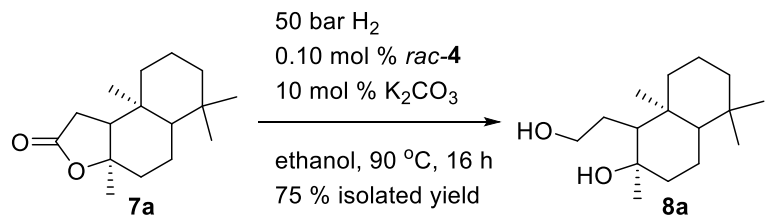

a. Reaction conditions: $20.0 \mathrm{mmol}(R)-(+)$-Sclareolide, 0.02 mmol rac-4, $2.0 \mathrm{mmol} \mathrm{K}_{2} \mathrm{CO}_{3}, 50$ bar hydrogen gas, ethanol $(0.4 \mathrm{M}), 90{ }^{\circ} \mathrm{C}, 16 \mathrm{~h}$.

The highly efficient reactions possible with the chiral ester, Sclareolide, led us to consider the more challenging hydrogenations of $\alpha$-chiral esters. It is known that alkoxide bases cause epimerization of stereogenic centers alpha to ester functions, ${ }^{39-40}$ and our experiments with some of the esters used here confirm just how rapid this can be (Fig. S1). ${ }^{18}$ Therefore, the successful use of pre-activated catalysts to reduce $\alpha$-chiral esters has only been reported using precious metal systems, ${ }^{23-24}$ and since pre-activated catalysts are less stable and more expensive to produce, a better solution to this issue is needed. The need for this methodology initially arose in a synthesis of the key chiral building block for the synthesis of the antibiotic nemonoxacin. ${ }^{41}$ In our hands, we were unable to reduce the tri-benzylated glycine 9a using the pre-activated Ru system, Ru-MACHOborohydride. While it is perfectly possible, that further research would solve this problem using Ru systems, we examined the Mn catalyst under the weak base conditions and were delighted to find (S)-2-(dibenzylamino)pent-4en-1-ol, 10a could be formed with no loss of stereochemical integrity at as low temperature as $50{ }^{\circ} \mathrm{C}$ using $1 \mathrm{~mol} \%$ rac-4 and $10 \mathrm{~mol} \% \mathrm{~K}_{2} \mathrm{CO}_{3}$ (Table 2, entry 1 ). Following this success, other $\alpha$-chiral amino acid esters were tested (Table 2 , entries 2-4). We found that the amino functionality needed to be fully protected to ensure both full conversion and full retention of stereochemical integrity under the reaction conditions (free amino acid esters gave partially racemized products). Other amino acid derivatives were 
reduced more effectively at $110{ }^{\circ} \mathrm{C}$. Even at this temperature, no observable racemization of the stereo center was observed.

Table 2. Hydrogenation of $\alpha$-chiral esters ${ }^{a}$

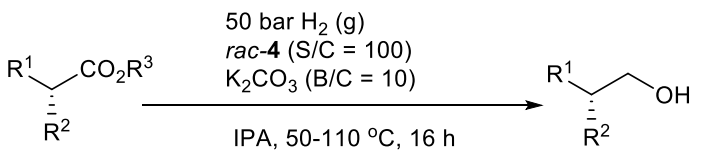

(ee]

a. Typical conditions: $1.00 \mathrm{mmol}$ substrate, $0.010 \mathrm{~mol} \mathrm{4}$, $0.10 \mathrm{mmol} \mathrm{K} \mathrm{CO}_{3}, 50$ bar hydrogen gas, ethanol or isopropanol $(0.4 \mathrm{M}), 50{ }^{\circ} \mathrm{C}, 16 \mathrm{~h}$ using 1 -methylnapthalene $(0.35 \mathrm{mmol})$ as internal standard; b. ee in \% with absolute configuration as shown; c. difference between product and starting material; $d$.
$\%$ conversion and isolated yield (in brackets), e. reaction carried out at $110{ }^{\circ} \mathrm{C}$.

With the successful hydrogenation of $\alpha$-amino acid esters, we decided to try the even more sensitive $\alpha$-aryl substituted chiral esters. Using $(S)$-ethyl naproxen (9e) as the test substrate, we initially varied several parameters to minimize the level of racemization and optimize the conversion. We observed a clear temperature dependence on the rate of racemization of $\mathbf{9 e}$ with higher temperatures leading to some racemization within a short time frame even using potassium carbonate as the base (Fig. S1). This indicated that we needed to carry out this reaction at relatively low temperature $\left(10 \mathrm{~mol} \% \mathrm{KOBu}^{\mathrm{t}}\right.$ racemized $9 \mathbf{e}$ within $10 \mathrm{~min}$ at $50{ }^{\circ} \mathrm{C}$ in isopropanol, whilst $10 \mathrm{~mol} \%$ $\mathrm{K}_{2} \mathrm{CO}_{3}$ left the $e e$ of $9 e$ unchanged after $1 \mathrm{~h}$, Fig. S1).

Next, we tested different solvents and catalyst loadings and found that isopropanol was superior to ethanol with regard to lower erosion of the enantiomeric excess. The use of higher catalyst loading showed lower erosion of enantiomeric excess due to higher rates of reduction (Table S2). The amount of base was found to be crucial to achieve good conversion with $10 \mathrm{~mol} \%$ of base found to give the best results.

Thus, ethyl naproxen could be reduced with no loss of stereogenic integrity. With these optimized conditions, we screened a number or $\alpha$ - and $\beta$-chiral esters (Table 2 , entries 5-12). (R)-ethyl 2-phenyl butyrate (9f), ( $S$ )-ethyl ibuprofen (9g) and (S)-ethyl 2-(4-chlorophenyl)-3methylbutyrate $(\mathbf{9 h})$ were all readily reduced under these conditions with minimal erosion of ee. $\beta$-chiral esters such as $(R)$-ethyl 3-phenylbutyrate (9i) and both $(R)$-ethyl nipecotonate $(\mathbf{9 j})$ and $c b z$ protected $(R)$-ethyl nipecotonate (9k) were reduced without any observable change in enantiomeric excess. (S)-1-hydromethyl-1,2,3,4tetrahydronaphthalene (101) as isolated with the lowest ee $(88 \%)$, which may reflect it being not very reactive (Table 2 , entry 12). 91 epimerize over time in the presence of 10 mol $\% \mathrm{~K}_{2} \mathrm{CO}_{3}$ without catalyst, with an erosion of $5 \%$ ee after $4 \mathrm{~h}$ at $50{ }^{\circ} \mathrm{C}$ (Figure S3).

In summary, we have developed a convenient protocol for the hydrogenation of achiral esters and lactones using low catalyst loading, benign weak base and alcoholic solvents. This protocol enables the reduction of $\alpha$-chiral esters with essentially no loss of enantiomeric purity.

\section{ASSOCIATED CONTENT}

\section{Supporting Information}

The Supporting Information is available free of charge on the ACS Publications website. Experimental details and compound structural data (PDF).

\section{AUTHOR INFORMATION}

\section{Corresponding Author}

* e-mail address: mc28@st-andrews.ac.uk

\section{ACKNOWLEDGMENT}


The authors thank the EPSRC for DTG funding for MBW. The technical support staff at St Andrews are also gratefully acknowledged. The research data supporting this publication can be accessed at: dx.doi.org/10.17630/29308cf7-b6b64b1b-809b-a12fe91b250f

\section{REFERENCES}

1. Clarke, M. L., Recent developments in the homogeneous hydrogenation of carboxylic acid esters. Catal. Sci. Technol. 2012, 2, 2418.

2. Werkmeister, S.; Neumann, J.; Junge, K.; Beller, M., PincerType Complexes for Catalytic (De)Hydrogenation and Transfer (De)Hydrogenation Reactions: Recent Progress. Chem.-Eur. J. 2015, 21, 12226-50.

3. Magano, J.; Dunetz, J. R., Large-Scale Carbonyl Reductions in the Pharmaceutical Industry. Org. Process Res. Dev. 2012, 16, 1156-1184.

4. Dub, P. A.; Ikariya, T., Catalytic Reductive Transformations of Carboxylic and Carbonic Acid Derivatives Using Molecular Hydrogen. ACS Catal. 2012, 2, 1718-1741.

5. Clarke M. L, Roff, G. J. Handbook of Homogeneous Hydrogenation. Wiley-VCH: Weinheim, 2007, 413-454

6. Zhang, J.; Leitus, G.; Ben-David, Y.; Milstein, D., Efficient homogeneous catalytic hydrogenation of esters to alcohols. Angew. Chem. Int. Ed. Engl. 2006, 45, 1113-1115.

7. Saudan, L. A.; Saudan, C. M.; Debieux, C.; Wyss, P., Dihydrogen reduction of carboxylic esters to alcohols under the catalysis of homogeneous ruthenium complexes: high efficiency and unprecedented chemoselectivity. Angew. Chem. Int. Ed. Engl. 2007, 46, 7473-7476.

8. Carpenter, I.; Eckelmann, S. C.; Kuntz, M. T.; Fuentes, J. A.; France, M. B.; Clarke, M. L., Convenient and improved protocols for the hydrogenation of esters using Ru catalysts derived from $(\mathrm{P}, \mathrm{P}),(\mathrm{P}, \mathrm{N}, \mathrm{N})$ and $(\mathrm{P}, \mathrm{N}, \mathrm{O})$ ligands. Dalton Trans. 2012, 41, 1013610140.

9. Spasyuk, D.; Smith, S.; Gusev, D. G., From esters to alcohols and back with ruthenium and osmium catalysts. Angew. Chem. Int. Ed. Engl. 2012, 51, 2772-2775.

10. Fuentes, J. A.; Smith, S. M.; Scharbert, M. T.; Carpenter, I.; Cordes, D. B.; Slawin, A. M.; Clarke, M. L., On the Functional Group Tolerance of Ester Hydrogenation and Polyester Depolymerisation Catalysed by Ruthenium Complexes of Tridentate Aminophosphine Ligands. Chem.-Eur. J. 2015, 21, 10851-10860.

11. Ogata, O.; Nakayama, Y.; Nara, H.; Fujiwhara, M.; Kayaki, Y., Atmospheric Hydrogenation of Esters Catalyzed by PNPRuthenium Complexes with an N-Heterocyclic Carbene Ligand. Org. Lett. 2016, 18, 3894-3897.

12. Wang, Z.; Chen, X. Y.; Liu, B.; Liu, Q. B.; Solan, G. A.; Yang, X. Z.; Sun, W. H., Cooperative interplay between a flexible PNN$\mathrm{Ru}$ (II) complex and a $\mathrm{NaBH}_{4}$ additive in the efficient catalytic hydrogenation of esters. Catal. Sci. Technol. 2017, 7, 1297-1304.

13. Qu, S.; Dai, H.; Dang, Y.; Song, C.; Wang, Z.-X.; Guan, H., Computational Mechanistic Study of Fe-Catalyzed Hydrogenation of Esters to Alcohols: Improving Catalysis by Accelerating Precatalyst Activation with a Lewis Base. ACS Catal. 2014, 4, 4377-4388.

14. Werkmeister, S.; Junge, K.; Wendt, B.; Alberico, E.; Jiao, H.; Baumann, W.; Junge, H.; Gallou, F.; Beller, M., Hydrogenation of Esters to Alcohols with a Well-Defined Iron Complex. Angew. Chem. Int. Ed. Eng. 2014, 53, 8722-8726.

15. Chakraborty, S.; Dai, H.; Bhattacharya, P.; Fairweather, N. T.; Gibson, M. S.; Krause, J. A.; Guan, H., Iron-Based Catalysts for the Hydrogenation of Esters to Alcohols. J. Am. Chem. Soc. 2014, 136, 7869-7872.

16. Elangovan, S.; Wendt, B.; Topf, C.; Bachmann, S.; Scalone, M.; Spannenberg, A.; Jiao, H.; Baumann, W.; Junge, K.; Beller, M., Im- proved Second Generation Iron Pincer Complexes for Effective Ester Hydrogenation. Adv. Synth. Catal. 2016, 358, 820-825.

17. (a) Zell, T.; Ben-David, Y.; Milstein, D., Unprecedented IronCatalyzed Ester Hydrogenation. Mild, Selective, and Efficient Hydrogenation of Trifluoroacetic Esters to Alcohols Catalyzed by an Iron Pincer Complex. Angew. Chem., Int. Ed. Engl, 2014, 53, 46854689. Iron catalysts can also be used for some other hydrogenations with high efficiency, for example: (b) Yu, R. P., Darmon, J. M., Hoyt, J. M., Margulieux, G. W., Turner, Z. R., Chirik, P. J., HighActivity Iron Catalysts for the Hydrogenation of Hindered, Unfunctionalized Alkenes. ACS Catal. 2012, 2, 1760-1764; (c) Morris, R. H., Smith, S. A. M., Lagaditis, P. O., Lough, A. J., Lüpke, A., Unsymmetrical Iron P-NH-P' Catalysts for the Asymmetric Pressure Hydrogenation of Aryl Ketones. Chem.- Eur. J. 2017, 23, 72127216.

18. Using carefully controlled conditions, racemization of lactate esters can be avoided using alkoxide bases, see: Kuriyama, W.; Matsumoto, T.; Ogata, O.; Ino, Y.; Aoki, K.; Tanaka, S.; Ishida, K.; Kobayashi, T.; Sayo, N.; Saito, T., Catalytic Hydrogenation of Esters. Development of an Efficient Catalyst and Processes for Synthesising (R)-1,2-Propanediol and 2-(1-Menthoxy)ethanol. Org. Process Res. Dev. 2012, 16, 166-171.

19. O, W. W. N.; Morris, R. H., Ester Hydrogenation Catalyzed by a Ruthenium(II) Complex Bearing an N-Heterocyclic Carbene Tethered with an "NH2" Group and a DFT Study of the Proposed Bifunctional Mechanism. ACS Catal. 2013, 3, 32-40.

20. Filonenko, G. A.; Aguila, M. J.; Schulpen, E. N.; van Putten, R.; Wiecko, J.; Muller, C.; Lefort, L.; Hensen, E. J.; Pidko, E. A., Bis-Nheterocyclic Carbene Aminopincer Ligands Enable High Activity in Ru-Catalyzed Ester Hydrogenation. J. Am. Chem. Soc. 2015, 137, 7620-7623

21. Tan, X.; Wang, Y.; Liu, Y.; Wang, F.; Shi, L.; Lee, K. H.; Lin, Z.; Lv, H.; Zhang, X., Highly efficient tetradentate ruthenium catalyst for ester reduction: especially for hydrogenation of fatty acid esters. Org. Lett. 2015, 7, 454-457.

22. Spasyuk, D.; Smith, S.; Gusev, D. G., Replacing Phosphorus with Sulfur for the Efficient Hydrogenation of Esters. Angew. Chem., Int. Ed. Engl. 2013, 52, 2538-2542.

23. Kuriyama, W.; Ino, Y.; Ogata, O.; Sayo, N.; Saito, T., A Homogeneous Catalyst for Reduction of Optically Active Esters to the Corresponding Chiral Alcohols without Loss of Optical Purities. Adv. Synth. Catal. 2010, 352, 92-96.

24. Kuriyama, W.; Matsumoto, T.; Ino, Y.; Ogata, O., Novel ruthenium carbonyl complex having a tridentate ligand and manufacturing method and usage thereof. EP2492275 A1, 2012.

25. Gunanathan, C.; Milstein, D., Metal-Ligand Cooperation by Aromatization-Dearomatization: A New Paradigm in Bond Activation and "Green" Catalysis. Acc. Chem. Res. 2011, 44, 588-602.

26. Khusnutdinova, J. R.; Milstein, D., Metal-ligand cooperation. Angew. Chem. Int. Ed. Engl. 2015, 54, 12236-12273.

27. Fogler, E.; Iron, M. A.; Zhang, J.; Ben-David, Y.; Diskin-Posner, Y.; Leitus, G.; Shimon, L. J. W.; Milstein, D., Ru(0) and $\mathrm{Ru}(\mathrm{II})$ Nitrosyl Pincer Complexes: Structure, Reactivity, and Catalytic Activity. Inorg. Chem. 2013, 52, 11469-11479.

28. Mukherjee, A.; Nerush, A.; Leitus, G.; Shimon, L. J.; Ben David, Y.; Espinosa Jalapa, N. A.; Milstein, D., Manganese-Catalyzed Environmentally Benign Dehydrogenative Coupling of Alcohols and Amines to Form Aldimines and $\mathrm{H}_{2}$ : A Catalytic and Mechanistic Study. J. Am. Chem. Soc. 2016, 138, 4298-4301.

29. Milstein, D. B., E.; Gunathan, C.; Gnanaprakasam, B.; Zhang, J., Novel ruthenium complexes and their uses in processes form formation and/or hydrogenation of esters, amides and derivatives thereof. W0212052996 A2, 2012.

30. Guidelines from the European Medicines Agency can be found here: http://www.ema.europa.eu/docs/en_GB/

document_library/Scientific_guideline/2009/09/ 
WC500003586.pdf; in effect since 1 September 2008; see also Elemental Impurities in Drug Products, Food and Drug Administration draft guidance; http://www.fda.gov/ucm/groups/fdagovpublic/@fdagov-drugs-gen/documents/docment/

ucm509432.pdf.

31. Widegren, M. B.; Harkness, G. J.; Slawin, A. M. Z.; Cordes, D. B.; Clarke, M. L., A Highly Active Manganese Catalyst for Enantioselective Ketone and Ester Hydrogenation. Angew. Chem. Int. Ed. Engl. 2017, 56, 5825-5828. One example of a ketone using a weak base was reported (with the other reactions using alkoxide bases)

32. Elangovan, S.; Garbe, M.; Jiao, H.; Spannenberg, A.; Junge, K.; Beller, M., Hydrogenation of Esters to Alcohols Catalyzed by Defined Manganese Pincer Complexes. Angew. Chem. Int. Ed. Engl. 2016, 55, 15364-15368.

33. Espinosa-Jalapa, N. A.; Nerush, A.; Shimon, L. J. W.; Leitus, G.; Avram, L.; Ben-David, Y.; Milstein, D., Manganese-Catalyzed Hydrogenation of Esters to Alcohols. Chem.-Eur. J. 2017, 23, 59345938.

34. Kelly, C. M.; McDonald, R.; Sydora, O. L.; Stradiotto, M.; Turculet, L., A Manganese Pre-Catalyst: Mild Reduction of Amides, Ketones, Aldehydes, and Esters. Angew. Chem. Int. Ed. Engl. 2017, 56, 15901-15904.

35. (a) van Putten, R.; Uslamin, E. A.; Garbe, M.; Liu, C.; Gonzalez-de-Castro, A.; Lutz, M.; Junge, K.; Hensen, E. J. M.; Beller, M.; Lefort, L.; Pidko, E. A., Non-Pincer-Type Manganese Complexes as Efficient Catalysts for the Hydrogenation of Esters. Angew. Chem. Int. Ed. Engl. 2017, 56, 7531-7534. Manganese catalysts are also showing promise for transfer hydrogenation, examples include: (b) Wand, D.; Bruneau-Voisine, A.; Sortais, J. B., Practical (asymmetrical) transfer hydrogenation of ketones catalyzed by manganese with (chiral) diamine ligands. Catal. commun. 2018, 105, 31-36; (c) Perez, M., Elangovan, S., Spannenberg, A., Junge, K., Beller, M., Molecularly Defined Manganese Pincer Complexes for Selective Transfer Hydrogenation of Ketones. ChemSusChem 2017, 10, 8386; (d) Zirakzadeh, A., de Aguiar, Sara R. M. M., Stöger, B., Widhalm, M., Kirchner, K., Enantioselective Transfer Hydrogenation of Ketones Catalyzed by a Manganese Complex Containing an Unsymmetrical Chiral PNP' Tridentate Ligand. ChemCatChem, 2017, 9, 1744-1748. For examples of other manganese catalysed reductive processes see: (e) Elangovan, S.; Neumann, J.; Sortais, J. B.; Junge, K.; Darcel, C.; Beller, M., Efficient and selective Nalkylation of amines with alcohols catalysed by manganese pincer complexes. Nat. Commun. 2016, 7, 12641.; (f) Mukherjee, A.; Nerush, A.; Leitus, G.; Shimon, L. J.; Ben David, Y.; Espinosa Jalapa, N. A.; Milstein, D., Manganese-Catalyzed Environmentally Benign Dehydrogenative Coupling of Alcohols and Amines to Form Aldimines and $\mathrm{H}_{2}$ : A Catalytic and Mechanistic Study. J. Am. Chem. Soc. 2016, 138, 4298-4301.; (g) Pena-Lopez, M.; Piehl, P.; Elangovan, S.; Neumann, H.; Beller, M., Manganese-Catalyzed HydrogenAutotransfer C-C Bond Formation: alpha-Alkylation of Ketones with Primary Alcohols. Angew. Chem. Int. Ed. Engl. 2016, 55, 14967-14971.; (h) Bruneau-Voisine, A.; Wang, D.; Dorcet, V.; Roisnel, T.; Darcel, C.; Sortais, J. B., Mono-N-methylation of anilines with methanol catalyzed by a manganese pincer-complex. $J$. Catal. 2017, 347, 57-62. For more recent reviews see: (i) Garbe, M.; Junge, K.; Beller, M., Homogenous Catalysis by manganese-based pincer complexes. Eur. J. Org. Chem. 2017, 2017, 4344-4362.; (j) Kallmeier, F.; Kempe, R., Manganese complexes for (de)hydrogenation catalysis: A comparison to cobalt and iron catalysts. Angew. Chem. Int. Ed. 2018, 2, 46-60.; (k) Filonenko, G. A.; van Putten, R; Hemsen, E. J. M.; Pidko, E. A., Catalytic (de)hydrogenation promoted by non-precious metals - Co, Fe and $\mathrm{Mn}$ : recent advances in an emerging field. Chem. Soc. Rev. 2018, 47, 1459-1483.

36. Mori, K.; Tamura, H., Triterpenoid total synthesis, I. Synthesis of ambrein and Ambrox®. Liebigs ann. 1990, 361-368.
37. Saudan, L. D., P.; Riedhauser J.-J.; Wyss, P., Hydrogenation of esters with $\mathrm{Ru} /$ bidentate ligands complexes. WO 2006/106483, 2006.

38. Quintaine, J.; Saudan S. D., Hydrogenation of esters with Fe/tridentate ligands complexes. WO 2015/091158 A1, 2015.

39. Ito, M.; Ootsuka, T.; Watari, R.; Shiibashi, A.; Himizu, A.; Ikariya, T., Catalytic Hydrogenation of Carboxamides and Esters by Well-Defined Cp*Ru Complexes Bearing a Protic Amine Ligand. J. Am. Chem. Soc. 2011, 133, 4240-4242.

40. Yang, X. H.; Yue, H. T.; Yu, N.; Li, Y. P.; Xie, J. H.; Zhou, Q. L., Iridium-catalyzed asymmetric hydrogenation of racemic alphasubstituted lactones to chiral diols. Chem. Sci. 2017, 8, 1811-1814.

41. Pittaway, R.; Fuentes, J. A.; Clarke, M. L., Diastereoselective and Branched-Aldehyde-Selective Tandem HydroformylationHemiaminal Formation: Synthesis of Functionalized Piperidines and Amino Alcohols. Org. Lett. 2017, 19, 2845-2848. 